\title{
Changes and Leadership at CJNS
}

Can. J. Neurol. Sci. 2006; 33: 259

There have been some important changes at CJNS. It is with great pleasure that I announce three new Associate Editors for the journal.

Dr. Jay Max Findlay is a Clinical Professor of Neurosurgery, Faculty of Medicine, University of Alberta. Dr. Findlay has been an international leader in the field of vascular Neurosurgery having published upwards of 100 original papers (including a number of superb pieces published in CJNS) and chapters including an edited textbook on vasospasm. Dr. Findlay has served as a member of the Editorial Board of CJNS and brings a critically important perspective to the journal. He will be a valuable Associate Editor.

Dr. Michael Shevell is a Professor in the Departments of Neurology/Neurosurgery and Pediatrics at McGill University in the Division of Pediatric Neurology at Montreal Children's

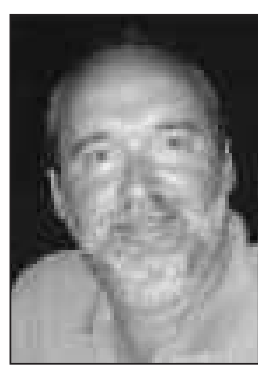

Michael Shevell Hospital. He is a recognized international authority on Neurodevelopmental disabilities and has written several important and sobering articles on Neurology in the Third Reich. Dr. Shevell has published upwards of 150 original papers and chapters including an edited textbook on Clinical and Scientific Aspects of Neurodevelopmental Disabilities. Dr. Shevell has served as a member of the Editorial Board of CJNS, has contributed a number of important articles to the journal and will be a valuable Associate Editor.

Dr. Bryan Young is a Professor in the Divisions of Neurology (Department of Clinical Neurological Sciences) and Critical Care Medicine (Department of Medicine) at the University of Western Ontario. Dr. Young is an international leader in Clinical Neurophysiology (EEG, Evoked Potentials) and Disorders of Consciousness. He has published upwards of 200 original articles and chapters and 7 books including a seminal text on Coma and Impaired Consciousness. Dr. Young has served as a member of the Editorial Board of CJNS, has published important articles in the journal and will be a valuable Associate

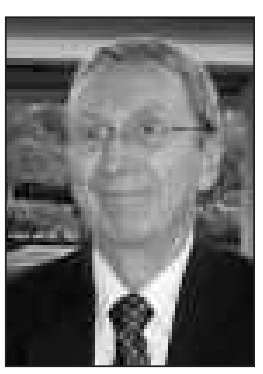

Bryan Young
Editor. Last year, CJNS awarded Dr. Young the "Reviewer of the Year" distinction for his numerous high quality reviews for us.

Our new Associate Editors add significant prestige to CJNS and will serve us well.

While welcoming them, I also thank our two Associates who are stepping down in that role this year, but hopefully not too far away. Dr. Andres Lozano has served as Associate Editor for CJNS since 1998 working with both Drs. James Sharpe and myself. Dr. Lozano has been of considerable value to CJNS over this time, dealing with numerous Neurosurgical papers and offering very important perspectives. I am indebted to him for his input. Dr. William Fletcher served as an Associate Editor for CJNS since 2000. He has provided a critical local sounding board for CJNS issues and has helped in a wide range of Neurological papers. I am also grateful for his input.

Several new members of the Editorial Board will join us. They include Drs. Brian Toyota (Neurosurgery, Vancouver), Elaine Wirrell (Child Neurology, Calgary), David Fortin (Neurosurgery, Sherbrooke) and Brian Weinshenker (Rochester, $\mathrm{MN})$. Dr. Peter Richardson will be stepping down and I thank him for his input.

I am also pleased to report that the Canadian Congress of Neurological Sciences (CCNS) has selected Dan Morin to be the organization's Chief Executive Officer. Sally Gregg, our Executive Director, will continue working with the CJNS (and CCNS) on a part-time basis during the critical transition phase in leadership. I will stay on as your Editor-in-Chief for two further years.

The Canadian Journal of Neurological Sciences is looking forward to your contributions. It is important to remember that these should be submitted in our direction first, whether in Clinical or Basic Neurosciences. We have a superb team, complemented by outstanding contributions from our Neurosciences community. 